\title{
Progesterone and $20 \alpha$-dihydroprogesterone in sheep: a model of their distribution and metabolism
}

\author{
J. Y. F. Paterson, Cecelia A. Bedford, F. A. Harrison and R. B. Heap \\ A.R.C. Institute of Animal Physiology, Babraham, Cambridge CB2 4AT, U.K.
}

\begin{abstract}
Summary. The rates of metabolism of progesterone and 20 $\alpha$-dihydroprogesterone (20 $\alpha$-diHP) in sheep have been measured during and after the infusion of tracer amounts of $\left[{ }^{3} \mathrm{H}\right]$ progesterone. There were significant differences in the blood concentration of $\left[{ }^{3} \mathrm{H}\right]$ progesterone between experiments, but these were not attributable to the stage of gestation or to the difference between pregnant and non-pregnant animals. The mean ( \pm S.E.M.) metabolic clearance rate of progesterone was $3 \cdot 277 \pm$ 0.239 litres blood $/ \mathrm{min}$.

The simplest model of the distribution of progesterone was one containing two pools, $V_{1}[P]$ and $V_{2}[P]$, where $[P]$ is the blood concentration of progesterone, and in 23 experiments on 7 sheep the mean pool dimensions were $7 \cdot 8[\mathrm{P}] \mu \mathrm{g}$ and $70[\mathrm{P}] \mu \mathrm{g}$, respectively. This model was developed to include the formation of $20 \alpha$-diHP from progesterone. Progesterone appeared to be the major source of $20 \alpha$-diHP, though this did not seem to be an obligatory metabolite. The parameters obtained gave comparably low residual deviations for both labelled steroids and were consistent with other observations made on progesterone clearance.
\end{abstract}

\section{Introduction}

Studies on progesterone metabolism in the sheep have shown that the clearance rate of the hormone from blood is high, ranging from 2.7 litres $/ \mathrm{min}$ in the oestrous cycle, $3.48 \mathrm{litres} / \mathrm{min}$ in pregnancy, and up to 5.02 litres $/ \mathrm{min}$ in lactational anoestrus. The production rate is about $6 \mu \mathrm{g} / \mathrm{min}$ when a $\mathrm{CL}$ is fully functional, and as high as $72 \mu \mathrm{g} / \mathrm{min}$ towards the end of gestation when placental secretion is at its greatest (Bedford, Harrison \& Heap, 1972). In further studies it was found that the efficiency of splanchnic extraction of progesterone was $92 \%$, and that splanchnic clearance accounted for $27 \%$ of the metabolic clearance rate of progesterone (Bedford et al., 1974).

Short \& Rowell (1962) studied the kinetics of progesterone metabolism in sheep using a single injection of a large mass of $\left[{ }^{14} \mathrm{C}\right]$ progesterone and their results indicated that the rate of progesterone metabolism did not change during the second half of gestation. Other studies in women resulted in the hypothesis that progesterone was distributed in the body within two theoretical pools and estimations were made of their volumes and the half-life of progesterone they contained (Little, Tait, Tait \& Erlenmeyer, 1966).

A notable feature of progesterone metabolism in the sheep is the relatively high concentration of circulating $20 \alpha$-dihydroprogesterone (20 $\alpha$-diHP) (Short \& Moore, 1959). This is probably formed from progesterone (Bedford et al., 1972) in extra-splanchnic organs such as the kidney (Bedford et al., 1973). The post-infusion clearance of labelled progesterone and 20 $\alpha$-diHP from blood allows the measurement through modelling of the rate constants for the conversion of progesterone to $20 \alpha$-diHP, as examined in the present paper.

\section{Materials and Methods}

\section{Animals and techniques}

Sheep. Welsh Mountain, Clun Forest and Merino $\times$ Welsh Mountain sheep were used. Details 
of the animals, their feeding and management have been described previously (Bedford et al., 1972).

Progesterone infusion. $\left[7 \alpha_{-}{ }^{3} \mathrm{H}\right]$ Progesterone, sp. act. $>8 \cdot 5 \mathrm{Ci} / \mathrm{mmol}$, was infused at a constant rate (approx. $1 \mu \mathrm{Ci} / \mathrm{min},<40 \mathrm{ng} / \mathrm{min}$ ) into a jugular vein for $3.5 \mathrm{hr}$. Three or four blood samples of $10-20 \mathrm{ml}$ were taken from the contralateral carotid artery or jugular vein at 15-20 min intervals during the last hour of infusion (between 14.00 and 17.00 hours to minimize possible effects of any diurnal variation).

After the constant infusion of labelled progesterone was stopped, a series of blood samples $(7 \mathrm{ml}$ each) was taken $0 \cdot 5,1,2,3,4$ and 5 min later, followed by further samples $(12 \mathrm{ml}$ each) at 15, 30, 45 and $60 \mathrm{~min}$. All samples were immediately placed in chilled vessels, laked with distilled water and stored at $-15^{\circ} \mathrm{C}$.

Further details of the infusion procedure are given by Bedford et al. (1972).

Analysis of blood samples. The concentrations of radioactive progesterone and 20 $\alpha$-diHP were measured according to the technique of Bedford et al. (1972). The specific activity of progesterone was calculated from the endogenous blood progesterone concentration determined by a competitive protein-binding technique described elsewhere (Bedford et al., 1972).

\section{Mathematical methods}

Exponential curve fitting. It will be shown that the specific radioactivity of progesterone in blood during and after infusion of labelled progesterone can be fitted by a sum of two exponential terms. The simplest model of the distribution of progesterone which would be described by such a function is one, containing two pools, whose general form is:

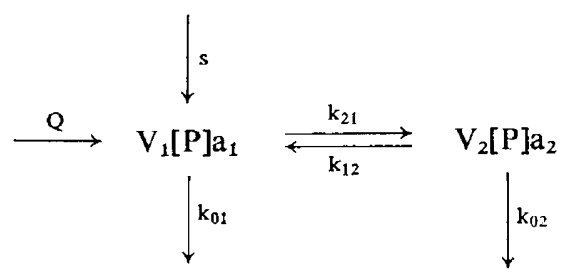

where [P] is the concentration of progesterone in blood, the sizes of the two pools are represented by $V_{1}[P]$ and $V_{2}[P]$, and their specific activities by $a_{1}$ and $a_{2}$, during infusion of labelled progesterone at $Q \mu \mathrm{Ci} / \mathrm{min}$ and at a secretion rate of $\mathrm{s} \mu \mathrm{g} / \mathrm{min} ; \mathrm{k}_{i j}$ is the rate constant for the transfer of progesterone from pool $\mathrm{j}$ to pool $\mathrm{i} ; \mathrm{k}_{\mathrm{ol}}$ represents irreversible catabolism in pool $\mathrm{i}$.

The rates of change of the specific activities are given by the differential equations:

$$
\begin{gathered}
V_{1}[P] \frac{d a_{1}}{d t}=Q-\left(k_{01}+k_{21}\right) V_{1}[P] a_{1}+k_{12} V_{2}[P] a_{2} \\
V_{2}[P] \frac{d a_{2}}{d t}=k_{21} V_{1}[P] a_{1}-\left(k_{02}+k_{12}\right) V_{2}[P] a_{2}
\end{gathered}
$$

During infusion of labelled progesterone, the solutions of these equations are:

$$
\begin{gathered}
a_{1}(t)=\frac{\left(k_{02}+k_{12}\right) Q}{\alpha_{1} \alpha_{2} V_{1}[P]}\left\{1-\frac{\alpha_{1} \alpha_{2}-\alpha_{2}\left(k_{02}+k_{12}\right)}{\left(\alpha_{1}-\alpha_{2}\right)\left(k_{02}+k_{12}\right)} e^{-\alpha_{1} t}+\frac{\alpha_{1} \alpha_{2}-\alpha_{1}\left(k_{02}+k_{12}\right)}{\left(\alpha_{1}-\alpha_{2}\right)\left(k_{02}+k_{12}\right)} e^{-\alpha_{2} t}\right\} \\
a_{2}(t)=\frac{\left(k_{02}+k_{12}\right) Q}{\alpha_{1} \alpha_{2} V_{1}[P]}\left\{1+\frac{\alpha_{2}}{\left(\alpha_{1}-\alpha_{2}\right)} e^{-\alpha_{1} t}-\frac{\alpha_{1}}{\left(\alpha_{1}-\alpha_{2}\right)} e^{-\alpha_{2} t}\right\}
\end{gathered}
$$

where $t$ is time ( $\mathrm{min}$ ) from the beginning of infusion and

$$
\alpha=\left\{\left(\mathrm{k}_{01}+\mathrm{k}_{02}+\mathrm{k}_{12}+\mathrm{k}_{21}\right) \pm \sqrt{\left(\mathrm{k}_{01}+\mathrm{k}_{02}+\mathrm{k}_{12}+\mathrm{k}_{21}\right)^{2}-4\left(\mathrm{k}_{01} \mathrm{k}_{02}+\mathrm{k}_{01} \mathrm{k}_{12}+\mathrm{k}_{02} \mathrm{k}_{21}\right)}\right\} / 2
$$

If the infusion of labelled progesterone is sufficiently long to establish the equilibrium specific 
activity $Q\left(k_{02}+k_{12}\right) /\left(\alpha_{1} \alpha_{2} V_{1}[P]\right)$, then when infusion is stopped the specific activities are given by:

$$
\begin{gathered}
\mathrm{a}_{1}\left(\mathrm{t}^{\prime}\right)=\frac{\left(\mathrm{k}_{02}+\mathrm{k}_{12}\right) \mathrm{Q}}{\alpha_{1} \alpha_{2} \mathrm{~V}_{1}[\mathrm{P}]}\left\{\frac{\alpha_{1} \alpha_{2}-\alpha_{2}\left(\mathrm{k}_{02}+\mathrm{k}_{12}\right)}{\left(\alpha_{1}-\alpha_{2}\right)\left(\mathrm{k}_{02}+k_{12}\right)} \mathrm{e}^{-\alpha_{1} \mathrm{t}^{\prime}}-\frac{\alpha_{1} \alpha_{2}-\alpha_{1}\left(\mathrm{k}_{02}+\mathrm{k}_{12}\right)}{\left(\alpha_{1}-\alpha_{2}\right)\left(\mathrm{k}_{02}+\mathrm{k}_{12}\right)} \mathrm{e}^{-\alpha_{2} \mathrm{t}^{\prime}}\right\} \\
\mathrm{a}_{2}\left(\mathrm{t}^{\prime}\right)=\frac{\left(\mathrm{k}_{02}+\mathrm{k}_{12}\right) \mathrm{Q}}{\alpha_{1} \alpha_{2} \mathrm{~V}_{1}[\mathrm{P}]}\left\{-\frac{\alpha_{2}}{\left(\alpha_{1}-\alpha_{2}\right)} \mathrm{e}^{-\alpha_{1} \mathrm{t}^{\prime}}+\frac{\alpha_{1}}{\left(\alpha_{1}-\alpha_{2}\right)} \mathrm{e}^{-\alpha_{2} \mathrm{t}^{\prime}}\right\}
\end{gathered}
$$

where $t^{\prime}$ is time ( $\mathrm{min}$ ) from the end of infusion and $\alpha$ is as defined in Equation 5.

These equations contain six parameters, four rate constants and two pool sizes. If only one specific activity is measured, e.g. $a_{1}(t)$ and $a_{1}\left(t^{\prime}\right)$, then only five parameters can be determined uniquely; the sixth parameter can only be estimated if the model is constrained in some way.

It can be seen that the equilibrium specific activity and the exponential constants and coefficients are common to Equation 3 and Equation 6 for $a_{1}$. A continuous exponential function was fitted using Equations 3, 5 and 6 to the measured values of progesterone specific activity in blood, $a_{1}(t)$ and $a_{1}\left(t^{\prime}\right)$. The optimum values for the parameters were estimated using the simplex method of Nelder \& Mead (1965).

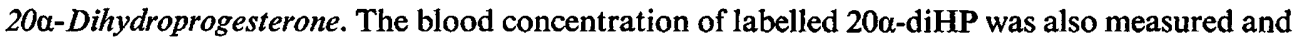
was found to be related to the blood concentration of labelled progesterone (Bedford et al., 1973). To investigate this relationship it was postulated that progesterone in both pools could be converted

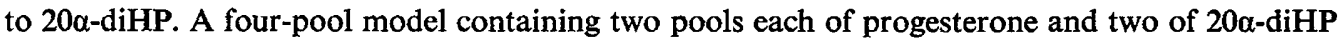
was examined. The simplest solution was to assume that in both progesterone pools the same proportion was converted to 20 $\alpha$-diHP which implies that progesterone and 20 $\alpha$-diHP occupy the same distribution volumes. $V_{1}, k_{1 j}$ and $[P]$ have been defined above, and [D] is the blood concentration of $20 \alpha$-diHP.

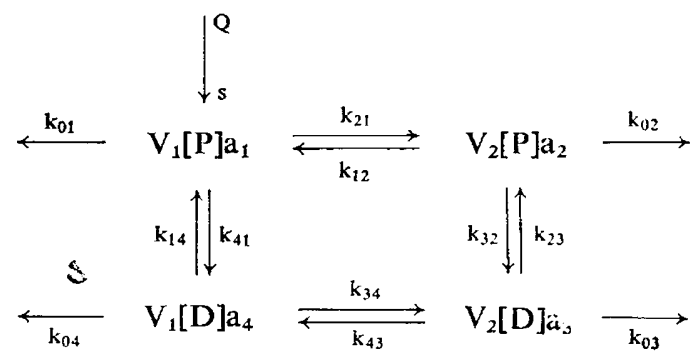

This model is described by four differential equations:

$$
\begin{gathered}
V_{1}[P] \frac{d a_{1}}{d t}=Q-\left(k_{01}+k_{21}+k_{41}\right) V_{1}[P] a_{1}+k_{12} V_{2}[P] a_{2}+k_{14} V_{1}[D] a_{4} \\
V_{2}[P] \frac{d a_{2}}{d t}=k_{21} V_{1}[P] a_{1}-\left(k_{02}+k_{12}+k_{32}\right) V_{2}[P] a_{2}+k_{23} V_{2}[D] a_{3} \\
V_{2}[D] \frac{d a_{3}}{d t}=k_{32} V_{2}[P] a_{2}-\left(k_{03}+k_{23}+k_{43}\right) V_{2}[D] a_{3}+k_{34} V_{1}[D] a_{4} \\
V_{1}[D] \frac{d a_{4}}{d t}=k_{41} V_{1}[P] a_{1}+k_{43} V_{2}[D] a_{3}-\left(k_{04}+k_{14}+k_{34}\right) V_{1}[D] a_{4}
\end{gathered}
$$

These equations were solved numerically using arbitrary values of parameters by the Runge-KuttaMerson method (Gear, 1971). About 1 min of computer time was required for each solution for a $3.5 \mathrm{hr}$ infusion, and $1 \mathrm{hr}$ post-infusion. It was not practicable to link this method to a parameteroptimization procedure which might require several hundred iterations. Accordingly, the parameters were adjusted systematically to minimize the sum of squares of differences between measured and computed values of labelled $20 \alpha$-diHP concentrations. 


\section{Results} Blood progesterone and $\left[{ }^{3} H\right]$ progesterone concentrations during and after intravenous infusion of
$\left[{ }^{3} \mathrm{H}\right]$ progesterone

$\left[{ }^{3} \mathrm{H}\right]$ Progesterone was infused at about $1.0 \mu \mathrm{Ci} / \mathrm{min}$ into a jugular vein for $3.5 \mathrm{hr}$. Blood samples were taken from the contralateral carotid artery or jugular vein during the last hour of infusion and during $1 \mathrm{hr}$ after the end of infusion. Blood progesterone and $\left[{ }^{3} \mathrm{H}\right]$ progesterone concentrations were measured as described above.

In those animals not provided with an exteriorized carotid artery (Table 1) the concentrations measured in jugular venous blood were adjusted for extraction of progesterone by the head (mean $25 \pm 3 \%$ ) to give estimated arterial concentrations. A continuous exponential function was fitted to the specific activity of progesterone in arterial blood by the procedure described above.

Results from 17 experiments on pregnant ewes and 6 experiments on non-pregnant ewes are shown in Table 1. For statistical analysis the measured $\left[{ }^{3} \mathrm{H}\right]$ progesterone concentrations were adjusted to a standard infusion rate $(1.0 \mu \mathrm{Ci} / \mathrm{min})$. They were then adjusted to a set of standard sampling times by interpolation using the individual exponential functions, retaining the deviations between measured and computed concentrations. The concentration of $\left[{ }^{3} \mathrm{H}\right]$ progesterone for the pooled

Table 1. Arterial progesterone concentration and computed $\left[{ }^{3} \mathrm{H}\right]$ progesterone time curves during and after infusion of $\left[{ }^{3} \mathrm{H}\right]$ progesterone in sheep

\begin{tabular}{|c|c|c|c|c|c|c|c|c|}
\hline \multirow[b]{2}{*}{ Sheep* } & \multirow{2}{*}{$\begin{array}{c}\text { Reproductive } \\
\text { state } \dagger \\
\text { (days) }\end{array}$} & \multirow[b]{2}{*}{$\begin{array}{l}\text { Progesterone } \\
\text { (ng/ml) }\end{array}$} & \multirow{2}{*}{$\begin{array}{l}\text { Infusion } \\
\text { rate } \\
(\mu \mathrm{Ci} / \mathrm{min})\end{array}$} & \multicolumn{5}{|c|}{$\left[{ }^{3} \mathrm{H}\right]$ progesterone } \\
\hline & & & & $\underset{(\mu \mathrm{Ci} / \text { litre })}{\mathbf{E}}$ & A & B & $\underset{\left(\min ^{-1}\right)}{\alpha}$ & $\begin{array}{c}\beta \\
\left(\min ^{-1}\right)\end{array}$ \\
\hline Lucy & $\mathbf{P} \quad(7)$ & $2 \cdot 3$ & 0.863 & 0.290 & 0.845 & 0.155 & 1.098 & 0.024 \\
\hline Merry§ & $P \quad(25)$ & $2 \cdot 2$ & 1.004 & $0 \cdot 260$ & 0.775 & 0.225 & 0.445 & 0.026 \\
\hline Maud§ & P (27) & 1.9 & 0.773 & 0.217 & 0.577 & 0.423 & $1 \cdot 429$ & $0 \cdot 169$ \\
\hline Lucy§ & P (43) & $3 \cdot 7$ & 0.628 & 0.236 & 0.695 & 0.305 & 0.299 & 0.014 \\
\hline Marigold $\S$ & P (50) & $0 \cdot 8$ & $0 \cdot 806$ & $0 \cdot 165$ & $0 \cdot 169$ & 0.831 & 0.926 & 0.103 \\
\hline Maud $\S$ & P (62) & $4 \cdot 2$ & 0.673 & 0.230 & 0.866 & 0.134 & $0 \cdot 541$ & 0.013 \\
\hline Frances & $P(66)$ & $4 \cdot 4$ & 0.640 & $0 \cdot 220$ & 0.761 & $0 \cdot 239$ & 0.349 & 0.021 \\
\hline Merry§ & P (67) & $5 \cdot 1$ & 0.845 & 0.214 & 0.653 & $0 \cdot 347$ & 0.455 & $0 \cdot 038$ \\
\hline Flossie & P (90) & $6 \cdot 4$ & 0.606 & 0.270 & 0.678 & $0 \cdot 322$ & 0.549 & 0.026 \\
\hline Lucy & P (99) & 4.9 & $1 \cdot 121$ & $0 \cdot 370$ & 0.695 & 0.305 & 0.325 & $0 \cdot 022$ \\
\hline Frances & $P(103)$ & $5 \cdot 5$ & 0.947 & 0.254 & $0-544$ & 0.456 & 0.550 & 0.059 \\
\hline Madeleine & $P(116)$ & $2 \cdot 5$ & $1 \cdot 174$ & 0.337 & 0.728 & 0.272 & $2 \cdot 987$ & 0.043 \\
\hline Frances & $P(122)$ & $4 \cdot 1$ & 0.734 & $0 \cdot 187$ & 0.506 & 0.494 & $2 \cdot 848$ & 0.061 \\
\hline Flossie & $P(124)$ & $15 \cdot 1$ & 0.857 & 0.291 & 0.691 & 0.309 & 0.756 & 0.010 \\
\hline Lucy & $P(134)$ & $3 \cdot 4$ & 0.937 & 0.306 & 0.635 & 0.365 & 0.751 & 0.032 \\
\hline Frances & P (139) & 3.9 & 0.840 & $0 \cdot 188$ & $0 \cdot 295$ & 0.705 & $7 \cdot 583$ & 0.083 \\
\hline Flossie & $P(145)$ & $9 \cdot 6$ & $1 \cdot 344$ & 0.390 & $0 \cdot 541$ & 0.459 & 0.698 & 0.035 \\
\hline Lucy & L (15) & $1 \cdot 0$ & $1 \cdot 022$ & 0.260 & 0.698 & $0 \cdot 302$ & 0.578 & 0.030 \\
\hline Lucy & C (6) & 0.2 & 0.787 & 0.285 & 0.834 & $0 \cdot 166$ & 0.354 & 0.009 \\
\hline Lucy & C (7) & $3 \cdot 2$ & 0.903 & 0.486 & 0.890 & $0 \cdot 110$ & 0.431 & 0.001 \\
\hline Merry & C (10) & 0.8 & 0.796 & 0.278 & 0.633 & 0.367 & $1 \cdot 510$ & 0.029 \\
\hline Maud & C (11) & $0 \cdot 8$ & 0.786 & $0 \cdot 241$ & 0.673 & 0.327 & 1.830 & 0.048 \\
\hline Marigold & C (12) & $3 \cdot 2$ & 0.988 & 0.181 & 0.475 & 0.525 & $1 \cdot 010$ & 0.092 \\
\hline \multicolumn{2}{|c|}{ Pooled (see text) } & & 1.000 & 0.305 & 0.687 & 0.313 & 0.602 & 0.029 \\
\hline
\end{tabular}

* Details of animals given by Bedford et al. (1972). Frances and Flossie had left adrenal transplants and the left ovary was transplanted to the neck during the first 6 weeks of pregnancy. The right ovary and right adrenal were removed before pregnancy.

$\dagger \mathrm{P}=$ pregnant, Day $\mathbf{0}=$ day of mating; $\mathrm{L}=$ lactating, Day $0=$ day of parturition; $\mathrm{C}=$ cyclic, Day $0=$ day of ovulation.

$\ddagger$ The exponential function fitted to blood $\left[{ }^{3} \mathrm{H}\right]$ progesterone is of the form:

$\left[{ }^{3} \mathrm{H}\right]$ progesterone $=\mathrm{E}\left(1-\mathrm{Ae}^{-\alpha t}-\mathrm{Be}^{-\beta t}\right) \mu \mathrm{Ci} /$ litre during infusion, and $=\mathrm{E}\left(\mathrm{Ae}^{-\alpha \mathrm{t}}+\mathrm{Be}^{-\beta t}\right) \mu \mathrm{Ci} /$ litre after infusion. $\S$ Results corrected for head extraction. 
data was $0.305\left(1.0-0.687 \mathrm{e}^{-0.602 t}-0.313 \mathrm{e}^{-0.029 t}\right) \mu \mathrm{Ci} /$ litre during infusion of $\left[{ }^{3} \mathrm{H}\right]$ progesterone where $t$ is time (min) from the beginning of the infusion, and $0.305\left(0 \cdot 687 \mathrm{e}^{-0.602 t^{\prime}}+0.313 \mathrm{e}^{-0.029 t^{\prime}}\right)$ $\mu \mathrm{Ci} /$ litre after the infusion where $t^{\prime}$ is time (min) after the end of the infusion.

\section{$\left[{ }^{3} H\right]$ Progesterone concentration during infusion}

The measured arterial $\left[{ }^{3} \mathrm{H}\right]$ progesterone concentrations during the last hour of infusion were analysed in a two-factor analysis of variance of 3 replicates in each of 23 experiments. The results of this analysis are summarized in Table 2. Differences attributable to sampling times did not contribute significantly to the variance. There were significant differences between experiments, and two-factor analyses of variance for each animal showed that there were within-animal and between-animal variations. These differences could not be associated with stage of gestation or with differences between pregnant and non-pregnant animals.

Table 2. Analysis of variance of arterial $\left[{ }^{3} \mathrm{H}\right]$ progesterone during and after infusion of $\left[{ }^{3} \mathrm{H}\right]$ progesterone

\begin{tabular}{lcrcc}
\hline \multicolumn{1}{c}{ Source } & Sum of squares & d.f. & Mean square & Ratio \\
\hline During infusion & & & & \\
$\quad$ Total & 0.366883 & 68 & & $12.86(P<0.001)$ \\
Between experiments & 0.315125 & 22 & 0.014324 & 1.24 \\
Between sample times & 0.002756 & 2 & 0.001378 & \\
$\quad$ Residual & 0.049002 & 44 & 0.001114 & \\
After infusion & & & & \\
$\quad$ Total & 0.468485 & 229 & & $12.77(P<0.001)$ \\
Between experiments & 0.271062 & 22 & 0.012321 & 0.73 \\
Between sample times & 0.006356 & 9 & 0.000706 & \\
$\quad$ Residual & 0.191066 & 198 & 0.000965 & \\
\hline
\end{tabular}

The $\left[{ }^{3} \mathrm{H}\right]$ progesterone concentrations could be fitted to a normal distribution (KolmogorovSmirnov test), with a mean of $0.306 \pm 0.073$ (S.D.) $\mu \mathrm{Ci} / \mathrm{litre}$ blood.

\section{$\left[{ }^{3} \mathrm{H}\right]$ Progesterone concentration after infusion}

The differences between measured and computed post-infusion $\left[{ }^{3} \mathrm{H}\right]$ progesterone concentrations were considered in a two-factor analysis of variance with 10 sampling times for each of 23 experiments (Table 2). The sum of squares attributable to sampling time was not significant. There were significant differences between experiments and these could not be associated with the differences during infusion, stage of gestation or difference between pregnant and non-pregnant animals.

The differences were distributed normally (Kolmogorov-Smirnov test) with a standard deviation of $0.043 \mu \mathrm{Ci} /$ litre blood.

\section{Pooled results: the metabolic clearance rate $(M C R)$ and distribution of progesterone}

Since the between-experiment differences in blood $\left[{ }^{3} \mathrm{H}\right]$ progesterone concentration appeared to be random, the standardized values for all experiments were pooled and a common exponential function fitted (Table 3).

The computed equilibrium concentration of $\left[{ }^{3} \mathrm{H}\right]$ progesterone for the pooled results was $0.305 \pm 0.073$ (S.D.) $\mu \mathrm{Ci} /$ litre blood, and since the infusion rate was $1.0 \mu \mathrm{Ci} / \mathrm{min}$ the metabolic clearance rate of progesterone was $3.277 \pm 0.239$ (S.D.) litre blood $/ \mathrm{min}$.

Clearances of progesterone by organs such as the liver and kidney are about 1.6 litre $\mathrm{blood} / \mathrm{min}$, or $50 \%$ of the MCR (Bedford et al., 1974). We have assumed that progesterone in blood is part of a central pool and that tissues such as liver, kidneys and head extract progesterone from that pool. 
Table 3. Observed and computed values for $\left[{ }^{3} \mathrm{H}\right]$ progesterone and $\left[{ }^{3} \mathrm{H}\right] 20 \alpha$-dihydroprogesterone in sheep blood

\begin{tabular}{|c|c|c|c|c|}
\hline \multirow{2}{*}{$\begin{array}{l}\text { Standardized } \\
\text { sampling } \\
\text { time* } \\
\text { (min) }\end{array}$} & \multicolumn{2}{|c|}{$\left[{ }^{3} \mathrm{H}\right]$ progesterone } & \multicolumn{2}{|c|}{$\left[{ }^{3} \mathrm{H}\right] 20 \alpha$-dihydroprogesterone } \\
\hline & $\begin{array}{c}\text { Standardized conc. }{ }^{\dagger} \\
(\mu \mathrm{Ci} / \text { litre; mean } \pm \text { S.E.M. })\end{array}$ & $\begin{array}{l}\text { Computed value } \ddagger \\
(\mu \mathrm{Ci} / \text { litre })\end{array}$ & $\begin{array}{c}\text { Standardized conc. } \dagger \\
(\mu \mathrm{Ci} / \text { litre; mean } \pm \text { S.E.M.) }\end{array}$ & $\begin{array}{l}\text { Computed value§ } \\
(\mu \mathrm{Ci} / \text { litre })\end{array}$ \\
\hline 145 & $0.302 \pm 0.0138$ & $0 \cdot 304$ & $0.158 \pm 0.0114$ & $0 \cdot 156$ \\
\hline 175 & $0.316 \pm 0.0179$ & $0 \cdot 305$ & $0.175 \pm 0.0243$ & $0 \cdot 159$ \\
\hline 205 & $0.302 \pm 0.0145$ & 0.305 & $0.154 \pm 0.0128$ & 0.160 \\
\hline \multicolumn{5}{|c|}{$210=$ infusion stopped } \\
\hline 0.5 & $0.243 \pm 0.0170$ & 0.249 & $0.161 \pm 0.0199$ & 0.159 \\
\hline $1 \cdot 0$ & $0.200 \pm 0.0166$ & 0.208 & $0.157 \pm 0.0170$ & $0 \cdot 157$ \\
\hline $2 \cdot 0$ & $0.157 \pm 0.0107$ & 0.153 & $0.141 \pm 0.0128$ & $0 \cdot 149$ \\
\hline $3 \cdot 0$ & $0.127 \pm 0.0094$ & 0.122 & $0.135 \pm 0.0127$ & $0 \cdot 140$ \\
\hline $4 \cdot 0$ & $0.110 \pm 0.0071$ & $0 \cdot 104$ & $0.125 \pm 0.0110$ & $0 \cdot 132$ \\
\hline $5 \cdot 0$ & $0.092 \pm 0.0057$ & 0.093 & $0.120 \pm 0.0103$ & $0 \cdot 125$ \\
\hline $15 \cdot 0$ & $0.053 \pm 0.0050$ & 0.062 & $0.099 \pm 0.0147$ & 0.095 \\
\hline $30 \cdot 0$ & $0.035 \pm 0.0037$ & 0.040 & $0.077 \pm 0.0150$ & 0.073 \\
\hline $45 \cdot 0$ & $0.029 \pm 0.0040$ & 0.026 & $0.055 \pm 0.0101$ & 0.055 \\
\hline $60 \cdot 0$ & $0.023 \pm 0.0034$ & 0.017 & $0.042 \pm 0.0097$ & $0 \cdot 040$ \\
\hline
\end{tabular}

* Concentrations adjusted by exponential interpolation (see text).

$\dagger$ Standardized to infusion rate of $1.0 \mu \mathrm{Ci} / \mathrm{min}$.

$\ddagger$ Fitted exponential function $0.305\left(0.687 \mathrm{e}^{-0.602 t}+0.313 \mathrm{e}^{-0.029 t}\right)$ after infusion.

$\S$ Numerical solution of differential equations.

The second pool may be regarded as an outer pool and the remaining $50 \%$ of the MCR must occur there. This constraint enables all the parameters of the two-pool model to be determined; these are shown in Table 4.

Table 4. Parameters of a two-pool model of progesterone distribution in sheep derived from the exponential function fitted to the pooled results (means \pm S.E.M.) from 23 experiments

\begin{tabular}{rlrl}
${ }^{*} \mathrm{k}_{01}=0.211 \pm 0.020 \mathrm{~min}^{-1} ;$ & For $[\mathrm{P}]=1.0 \mu \mathrm{g} / \mathrm{litre}$, \\
$\mathrm{k}_{21}=0.378 \pm 0.086 \mathrm{~min}^{-1} ;$ & $\mathrm{f}_{01}=1.639 \mu \mathrm{g} / \mathrm{min}$ \\
$\mathrm{k}_{12}=0.0185 \pm 0.0067 \mathrm{~min}^{-1} ;$ & $\mathrm{f}_{21}=2.937 \mu \mathrm{g} / \mathrm{min}$ \\
$\mathrm{k}_{02}=0.0233 \pm 0.0049 \mathrm{~min}^{-1} ;$ & $\mathrm{f}_{12}=1.298 \mu \mathrm{g} / \mathrm{min}$ \\
& $\mathrm{f}_{02}=1.639 \mu \mathrm{g} / \mathrm{min}$ \\
${ }^{*} \mathrm{~V}_{1}=7.76 \pm 0.8081$ blood equivalent $;$ & $V_{1}[\mathrm{P}]=7.76 \mu \mathrm{g}$ \\
$\mathrm{V}_{2}=70.2 \pm 10.71$ blood equivalent $;$ & $V_{2}[\mathrm{P}]=70.2 \mu \mathrm{g}$ \\
\hline
\end{tabular}

For an infusion rate of $1.0 \mu \mathrm{Ci} / \mathrm{min},\left[{ }^{3} \mathrm{H}\right]$ progesterone $=$ $0.305\left(1.0-0.687 \mathrm{e}^{-0.602 t}-0.313 \mathrm{e}^{-0.029 t}\right)$ during infusion, and $0.305\left(0.687 \mathrm{e}^{-0.602 t}+0.313 \mathrm{e}^{-0.029 t}\right)$ after infusion. The standard errors of the parameters were derived from the residual variance and the variance-covariance matrix generated in curve fitting.

* $k_{1 j}$ is the rate constant for flux from pool $j$ to pool $i$; the pool sizes ( $\mu \mathrm{g}$ progesterone) are represented by their equivalent volumes of arterial blood $\left(V_{i}\right)$ multiplied by the blood concentration of progesterone $[P] . f_{i j}$ is the flux of progesterone $(\mu \mathrm{g} / \mathrm{min})$ from pool $\mathrm{j}$ to pool $\mathrm{i}$.

\section{0a-Dihydroprogesterone}

Bedford et al. (1973) observed a close correlation between the equilibrium blood concentrations of $\left[{ }^{3} \mathrm{H}\right]$ progesterone and $\left[{ }^{3} \mathrm{H}\right] 20 \mathrm{a}$-diHP and noted that the slope of the regression line was similar to that observed by Short \& Moore (1959) for the endogenous concentrations of these steroids in blood. The correlation coefficients of labelled progesterone and $20 \alpha$-diHP, and of endogenous 
progesterone and 20 $\alpha$-diHP concentrations were not significantly different (Fisher's $z$ test, $P>0.25$ ) Accordingly, in deriving the model described in this paper we have assumed that progesterone is the predominant source of circulating $20 \alpha$-diHP, and that at equilibrium during infusion of labelled progesterone the specific radioactivities of the two steroids are the same.

The arterial blood concentrations of $\left[{ }^{3} \mathrm{H}\right] 20 \alpha$-diHP were adjusted to a standard infusion rate $(1.0 \mu \mathrm{Ci} / \mathrm{min})$ and to standard sampling times; the results are shown in Table 3.

\section{The formation and distribution of $20 \alpha-$ diHP}

In fitting the numerical solutions of Equations 8-11 to the observed 20 $\alpha$-diHP concentrations, some of the parameters, $V_{1}, V_{2}, k_{21}$ and $k_{12}$ can be obtained from Table 4. For this four-pool model, $\left(k_{01}+k_{41}\right)$ and $\left(k_{02}+k_{32}\right)$ were constrained to equal $k_{01}$ and $k_{02}$ respectively of Table 4 . From the measured arterial equilibrium concentrations of $\left[{ }^{3} \mathrm{H}\right]$ progesterone and $\left[{ }^{3} \mathrm{H}\right] 20 \alpha$-diHP concentrations, $[\mathrm{D}]=\mathbf{0} \cdot 529[\mathrm{P}]$.

In trials of the pairs of rate constants, $k_{14}$ and $k_{41}$ and $k_{32}$ and $k_{23}$, it appeared likely that there was little re-conversion of $20 \alpha$-diHP to progesterone. This was particularly evident in the very poor fit of the computed function and the observed concentrations of labelled 20a-diHP for values of $k_{41}$ and $k_{23}$ except when these were very small. The solution was not particularly sensitive to changes in the exchange of 20a-diHP between pools 3 and 4 . It was the four rate constants $k_{01}$ which had the greatest effect on the fit to the observed concentrations of labelled $20 \alpha$-diHP.

The final choice of parameters was influenced by the following considerations: $k_{01}$ was chosen to give a clearance of progesterone equal to $30 \% \mathrm{MCR}$, which is only slightly greater than the measured splanchnic clearance of progesterone (Bedford et al., 1974); $\mathrm{k}_{04}$ was chosen to give a similar clearance for $20 \alpha$-diHP; $k_{02}$ was chosen to be $(1 \cdot 0-0.529)$ of the clearance of progesterone in the outer pool and $\mathrm{k}_{03}$ was adjusted to give the required total MCR.

The final parameters and model are shown in Table 5 and the agreement between measured and computed $\left[{ }^{3} \mathrm{H}\right]$ progesterone and $\left[{ }^{3} \mathrm{H}\right] 20 \alpha$-diHP concentrations is shown in Text-fig. 1. The sum of squares of deviations between measured and computed values was 0.000448 (S.D. $=0.006$ ) for progesterone and 0.000478 (S.D. $=0.006)$ for $20 \alpha$-diHP.

The parameters shown in Table 5 are not unique, but they do provide a near-minimum sum of squares of deviations for $20 \alpha$-diHP.

Table 5. Parameters of a four-pool model of progesterone [P] and 20 $\alpha$-dihydroprogesterone (20 $\alpha$-diHP) [D] distribution and metabolism in sheep, obtained using Equations 8-11 (see text)

\begin{tabular}{llrl}
\hline$k_{01}=0.1288 \mathrm{~min}^{-1} ;$ & $\mathrm{f}_{01}=1.000 \mu \mathrm{g} / \mathrm{min}$ & $\mathrm{k}_{21}=0.3783 \mathrm{~min}^{-1} ;$ & $\mathrm{f}_{21}=2.937 \mu \mathrm{g} / \mathrm{min}$ \\
$\mathrm{k}_{02}=0.0110 \mathrm{~min}^{-1} ;$ & $\mathrm{f}_{02}=0.771 \mu \mathrm{g} / \mathrm{min}$ & $\mathrm{k}_{23}=\mathrm{small}$ & \\
$\mathrm{k}_{03}=0.0263 \mathrm{~min}^{-1} ;$ & $\mathrm{f}_{03}=0.977 \mu \mathrm{g} / \mathrm{min}$ & $\mathrm{k}_{32}=0.0124 \mathrm{~min}^{-1} ;$ & $\mathrm{f}_{32}=0.868 \mu \mathrm{g} / \mathrm{min}$ \\
$\mathrm{k}_{04}=0.1288 \mathrm{~min}^{-1} ;$ & $\mathrm{f}_{04}=0.529 \mu \mathrm{g} / \mathrm{min}$ & $\mathrm{k}_{34}=0.1938 \mathrm{~min}^{-1} ;$ & $\mathrm{f}_{34}=0.796 \mu \mathrm{g} / \mathrm{min}$ \\
$\mathrm{k}_{12}=0.0185 \mathrm{~min}^{-1} ;$ & $\mathrm{f}_{12}=1.298 \mu \mathrm{g} / \mathrm{min}$ & $\mathrm{k}_{41}=0.0823 \mathrm{~min}^{-1} ;$ & $\mathrm{f}_{41}=0.639 \mu \mathrm{g} / \mathrm{min}$ \\
$\mathrm{k}_{14}=$ small* & & $\mathrm{k}_{43}=0.0185 \mathrm{~min}^{-1} ;$ & $\mathrm{f}_{43}=0.687 \mu \mathrm{g} / \mathrm{min}$ \\
For $[\mathrm{P}]=1.0 \mu \mathrm{g} / \mathrm{litre},[\mathrm{D}]=0.53 \mu \mathrm{g} /$ litre and $\mathrm{s}=3.277[\mathrm{P}] \mu \mathrm{g} / \mathrm{min}$, & \\
$\mathrm{V}_{1}[\mathrm{P}]=7.76 \mu \mathrm{g}$ & & $\mathrm{V}_{2}[\mathrm{P}]=70.2 \mu \mathrm{g}$ & \\
$\mathrm{V}_{1}[\mathrm{D}]=4.11 \mu \mathrm{g}$ & & $\mathrm{V}_{2}[\mathrm{D}]=37.2 \mu \mathrm{g}$ & \\
\hline
\end{tabular}

Some of these parameters were taken from Table 4, and the remainder were obtained by adjustments which minimized the sum of squares of differences between measured and computed $\left[{ }^{3} \mathrm{H}\right] 20 \alpha$-diHP concentrations. All values are given in terms of progesterone. All fluxes of $20 \alpha-$ diHP are expressed as equivalents of progesterone, and should be divided by 0.529 to give flux as [D].

* Net exchanges were $<0 \cdot 1 \mu \mathrm{g} / \mathrm{min}$.

\section{Discussion}

The blood concentrations of $\left[{ }^{3} \mathrm{H}\right]$ progesterone and $\left[{ }^{3} \mathrm{H}\right] 20 \alpha$-dihydroprogesterone during and after the infusion of $\left[{ }^{3} \mathrm{H}\right]$ progesterone accord with the hypothesis that progesterone is distributed within 


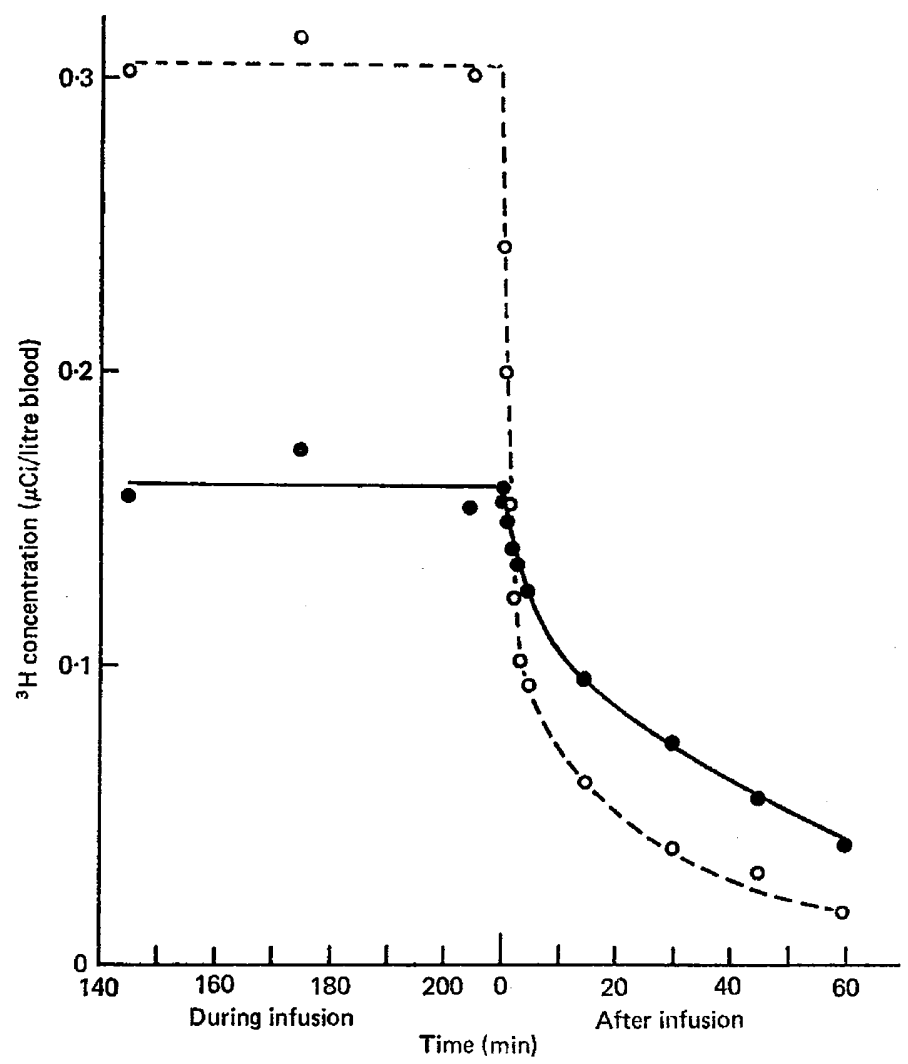

Text-fig. 1. Measured blood concentrations of $\left[{ }^{3} \mathrm{H}\right]$ progesterone $(O)$ and $\left[{ }^{3} \mathrm{H}\right] 20 \alpha$-dihydroprogesterone (๑), and the computed line for the blood concentration of $\left[{ }^{3} \mathrm{H}\right]$ progesterone (--) and $\left[{ }^{3} \mathrm{H}\right] 20 \alpha$-dihydroprogesterone ( $\longrightarrow$ during and after the infusion of $\left[{ }^{3} \mathrm{H}\right]$ progesterone. The computed values were obtained from Equations 8-11 (see text) and the parameters given in Table 5.

the body between two compartments. The amount of progesterone associated with a central pool, $7 \cdot 8[\mathrm{P}] \mu \mathrm{g}$, indicates a compartment greater than that of the vascular system and which in this study has been taken to include tissues such as liver, kidneys and head where the hormone is rapidly catabolized. In previous studies it was estimated that the clearance of progesterone within this pool represents about $50 \%$ of MCR (Bedford et al., 1974), so that the remaining $50 \%$ of catabolism occurs in a second, or outer pool whose dimension is apparently large, $70[\mathrm{P}] \mu \mathrm{g}$. The difference between the computed values for these two pools contrasts with the figures derived by Little $e t$ al. (1966) in human subjects in which values of about $12[\mathrm{P}] \mu \mathrm{g}$ and $15[\mathrm{P}]$ to $27[\mathrm{P}] \mu \mathrm{g}$ were obtained for the central and outer pools, respectively. The mean body weight of sheep used in our study, however, was $41 \mathrm{~kg}$ compared with a value of about $80 \mathrm{~kg}$ in the subjects investigated by Little et al. (1966). The dimension of the central pool corrected for body weight was therefore similar in the two species. Little et al. (1966) concluded that the rapid disappearance of progesterone from blood is caused by its rapid rate of metabolism. The large size of the outer pool in sheep implies that the extravascular concentration of progesterone is much greater than that in blood, and this may reflect the high lipid solubility of progesterone $(99.3 \mu \mathrm{mol} / \mu \mathrm{mol}$ phosphatidylcholine: Heap, Symons \& Watkins, 1970) and the presence of intracellular receptors or binding sites. The results indicate a clear species difference in the distribution of progesterone in an outer pool.

Another feature of progesterone metabolism in sheep which differs from that in man concerns the relatively high proportion of $20 \alpha$-diHP in circulation. The percentage conversion ratio of 20 $\alpha$-diHP:progesterone is at least 5 times greater in sheep (Bedford et al., 1972) than in women 
(Lin, Billiar \& Little, 1972). In sheep progesterone appears to be the major source of 20 -diHP, but does not seem to be an obligatory catabolite.

It was not practicable to optimize the parameters of a four-pool model mathematically, but those obtained gave equally low residual deviations for both labelled steroids and are consistent with other observations made on progesterone clearance. The clearance of progesterone from the central pool which does not produce $20 \alpha$-diHP, $\left(\mathrm{k}_{01} \mathrm{~V}_{1}[\mathrm{P}] \mathrm{a}=1.0\right.$ litre blood $\left./ \mathrm{min}=33 \% \mathrm{MCR}\right)$, is of the same order as splanchnic clearance of progesterone (1.155 litre min: Bedford et al., 1974). The clearance of 20 $\alpha$-diHP from the central pool, $\left(\mathrm{k}_{04} \mathrm{~V}_{1}[\mathrm{D}] \mathrm{a}_{4}=1.0\right.$ litres blood $\left./ \mathrm{min}\right)$, is of the same order as the observed splanchnic clearance of this steroid (1.138 litres $/ \mathrm{min})$. The computed rate of conversion of progesterone to $20 \alpha$-diHP in the central pool is greater than has been observed experimentally. However, this value was obtained from pooled results which came predominantly from pregnant ewes. The conversion to $20 \alpha$-diHP by the gravid uterus and by the kidney has not yet been studied in depth, and might be sufficient to account for the computed rate. Greater precision should also be

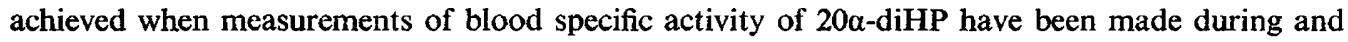
after the infusion of $\left[{ }^{3} \mathrm{H}\right] 20 \alpha$-diHP.

Criticism has been made of earlier work that the estimated MCR of progesterone was of the same order as cardiac output, and therefore physiologically dubious. In previous experiments it was shown that progesterone metabolism by maternal erythrocytes was negligible (Bedford et al., 1972) and unlikely to represent a significant source of error in the estimation of MCR. The current results also provide confirmation that steady state conditions were achieved since the mean MCR of progesterone computed from blood concentrations during and after the infusion ( $3 \cdot 277$ litres/min) was very similar to that calculated for the same experiments from blood concentrations during the infusion alone (3.397 litres/min; Bedford et al., 1972). The total efflux of progesterone from the central pool, $\left(k_{01}+k_{21}+k_{41}\right) V_{1}[P]$, is 4.58 litres blood/min and this comprises 1.53 litres/min at very high extraction efficiency with the remainder at about $56 \%$ extraction. Although this total efflux is not much smaller than cardiac output its validity could be checked in further experiments. Our model predicts that most major blood flows in the body should show an average extraction of $56 \%$ progesterone (excluding the splanchnic region). The model also requires that there should be a significant source of $20 \alpha$-diHP in the central pool in pregnant animals, and the uptake of progesterone by the gravid uterus should be investigated.

Further validation of the assumptions on which the model is based will be tested by the infusion

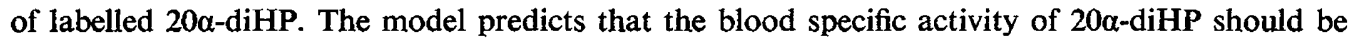
described by a double exponential, the outer pool of $20 \alpha$-diHP should be about 10 times greater than the central pool, and there should be little if any formation of labelled progesterone.

We thank Miss Grace Needham, Mrs Susan Young and Mr A. Henville for skilled technical assistance, and Dr N. J. Kuhn for a gift of $\left[4-{ }^{14} \mathrm{C}\right] 20 \alpha$-dihydroprogesterone.

\section{References}

Bedford, C.A., Harrison, F.A. \& Heap, R.B. (1972) The metabolic clearance rate and production rate of progesterone and the conversion of progesterone to 20a-hydroxypregn-4-en-3-one in the sheep. $J$. Endocr. 55, 105-118.

Bedford, C.A., Harrison, F.A. \& Heap, R.B. (1973) The kinetics of progesterone metabolism in the pregnant sheep. In The Endocrinology of Pregnancy and Parturition-Experimental Studies in the Sheep, pp. 83-93. Ed. C. G. Pierrepoint. Alpha Omega Alpha, Cardiff.

Bedrord, C.A., Harrison, F.A. \& Heap, R.B. (1974) The splanchnic, uterine, ovarian and adrenal uptake of progesterone and $20 \alpha$-dihydroprogesterone in the pregnant and non-pregnant sheep. J. Endocr. 62, 277-290.

GEAR, C.W. (1971) Numerical Initial Value Problems in Ordinary Differential Equations. Prentice-Hall, Englewood Cliffs, New Jersey.

Heap, R.B., Symons, A.M. \& Watkins, J.C. (1970) Steroids and their interactions with phospholipids: solubility, distribution coefficient and effect on potassium permeability of liposomes. Biochim. biophys. Acta 218, 482-495.

Lin, T.J., BilliaR, R.B. \& Little, B. (1972) Metabolic clearance rate of progesterone in the menstrual cycle. J. clin. Endocr. Metab. 35, 879-886. 
Little, B., TAIt, J.F., TAit, S.A.S. \& ERl.enmeyer, F. (1966) The metabolic clearance rate of progesterone in males and ovariectomized females. J. clin. Invest. 45, 901-912.

Nelder, J.A. \& Mead, R. (1965) A simplex method for function minimization. Comput. J. 7, 308-313.
SHORT, R.V. \& MOORE, N.W. (1959) Progesterone in blood. V. Progesterone and 20 $\alpha$-hydroxypregn-4-en3-one in the placenta and blood of ewes. $J$. Endocr. 19, 288-293.

ShorT, R.V. \& Rowell, J.G. (1962) The half-life of progesterone in the peripheral blood of a ewe at two stages of gestation. $J$. Endocr. 25, 369-374.

Received 30 May 1975 